\title{
Young children choose to reason with partners who submit to reason
}

DOI:

10.1016/j.cogdev.2019.100824

\section{Document Version}

Accepted author manuscript

Link to publication record in Manchester Research Explorer

\section{Citation for published version (APA):}

Domberg, A., Köymen, B., \& Tomasello, M. (2019). Young children choose to reason with partners who submit to reason. Cognitive Development. https://doi.org/10.1016/j.cogdev.2019.100824

\section{Published in:}

Cognitive Development

\section{Citing this paper}

Please note that where the full-text provided on Manchester Research Explorer is the Author Accepted Manuscript or Proof version this may differ from the final Published version. If citing, it is advised that you check and use the publisher's definitive version.

\section{General rights}

Copyright and moral rights for the publications made accessible in the Research Explorer are retained by the authors and/or other copyright owners and it is a condition of accessing publications that users recognise and abide by the legal requirements associated with these rights.

\section{Takedown policy}

If you believe that this document breaches copyright please refer to the University of Manchester's Takedown Procedures [http://man.ac.uk/04Y6Bo] or contact uml.scholarlycommunications@manchester.ac.uk providing relevant details, so we can investigate your claim.

\section{OPEN ACCESS}


15 Corresponding author: Andreas Domberg

16 E-mail address: domberg@posteo.de

17

\section{Children choose to reason with partners who submit to reason}

\author{
Andreas Domberg ${ }^{1}$, Bahar Köymen ${ }^{2}$, Michael Tomasello ${ }^{3-4}$ \\ ${ }^{1}$ Max Planck Institute for Human Development \\ ${ }^{2}$ University of Manchester \\ ${ }^{3}$ Duke University \\ ${ }^{4}$ Max Planck Institute for Evolutionary Anthropology
}

Article published in Cognitive Development 
Abstract

26 degrees of quality, irrespective of the facts under discussion. Partners often evaluate one

27 another's evaluation of reasons - one another's reasoning. Can children evaluate their

28 partner's judgment of the quality of reasons independent of objective truth? 5- and 7-year-

29 olds $(\mathrm{N}=122)$ chose among two partners for cooperation. In the experimental condition,

30 one acceded to a good reason, the other to a poor reason. In the control condition, each

31 agreed to a different good reason. Crucially, in both conditions, both partners arrived at

32 the wrong conclusion. Results suggested that 7-year-olds, and 5-year-olds to a lesser

33 degree, chose the partner who endorsed the good reason in the experimental condition, but

34 showed no preference for partners in the control condition. Thus, young children

35 distinguish good from poor reasons, even if neither leads to success, and choose partners

36 who do the same. 


\section{Children choose to reason with partners who submit to reason}

A rapidly growing literature characterizes reasoning as a social phenomenon. Mercier and Sperber $(2011,2017)$ argue that the main function of reasoning is for speakers to generate reasons that persuade group members of a given belief or decision, and for hearers to be critical of reasons when they encounter reasons presented by their partner. Tomasello (2014) further emphasizes the critical role that reasoning plays in collaborative decision-making, where groups need to find a good and justified solution benefiting all group members. In cooperative contexts, where the paramount goal is to come to a correct conclusion, people should submit to good reasons (over trying to win the argument) and prefer to reason with partners who do the same.

Children are vigilant social learners who selectively trust some information sources more than others. Four-year-olds trust accurate informants over inaccurate ones (Birch, Vauthier, \& Bloom, 2008; Corriveau \& Harris, 2009; Jaswal \& Neely, 2006; Koenig \& Harris, 2005). When accuracy cannot be verified and children need to attend instead to how informants justify their conclusions, 2- to 3-year-olds trust those who give good reasons for their proposals (e.g., "The dog went this way because I saw it go this way.") as opposed to circular ones (e.g., "The dog went this way because it went this way.”; Castelain et al., 2018, 2016; Corriveau \& Kurkul, 2014; Mercier et al., 2014, 2018). Similarly, Koenig (2012) showed that 4-year-olds trust conclusions that are based on good epistemic grounds such as perceptual access, (e.g., "I looked and I saw an apple in the box.") more than those based on wishful thinking (e.g., "I like apples. I want there to be apples in the box."). 
However, in these studies, it was often not clear whether the informants were actually right or wrong. A stricter test of children's sensitivity to the quality of reasons would be to investigate whether children still prefer an informant who produces good reasons, when both informants are wrong or have a false belief (e.g., "I saw that there is an apple in the box"-but the apple is no longer there). Moreover, in these studies, children were often asked to choose between individuals who produce reasons, instead of individuals who evaluate these reasons. Children's ability to identify and trust individuals who are able to distinguish good reasons from poor ones is a more advanced skill, because it requires children to not only evaluate the quality of the reasons and detach it from their own beliefs about the truth, but also to evaluate another person's evaluation of reasons.

In this study, therefore, we presented 5- and 7-year-old children with a cooperative game for which they needed a partner. Children observed two candidates together in a problem-solving task, namely, finding a lost paintbrush. Candidates heard together two reasons from two disagreeing informants about where the brush is. Crucially, the candidates were ignorant and the informants had a false belief about the location of the paintbrush. In the experimental condition, one informant produced a good reason based on eye-witness testimony ("Check the red box [incorrect location] because I saw it there yesterday"), and the other informant produced a poor reason based on color preference ("Check the yellow box [incorrect location] because yellow is my favorite color"). In the control condition, one informant produced the same good reason based on eye-witness testimony for the same incorrect proposal, and the other informant produced another good reason based on rules ("Check the yellow box [incorrect location] because we always put it there"). In both conditions, one candidate endorsed the good reason based on eye- 
84 witness testimony and the other endorsed the other reason. We predicted that in the

85 experimental condition, children would choose the candidate who endorsed the good

86 reason over the candidate who endorsed the poor reason; whereas in the control condition,

87 children would choose each candidate equally often, because both candidates endorsed a

88 good reason. We explored if there were any age differences. Although 5-year-olds are

89 good at evaluating reasons (Corriveau \& Kurkul, 2014; Mercier et al., 2014) and show

90 false belief understanding (Wellman, Cross, \& Watson, 2001; Wimmer \& Perner, 1983),

91 7-year-olds have been observed to be more strategic in their reasoning than 5-year-olds

92 (Domberg, Köymen, \& Tomasello, 2018). For instance, 7-year-olds withheld information

93 or reasons more often than 5-year-olds, if these reasons would prevent them from winning

94 a game against their peers. Moreover, 7-year-olds are better able to express why they

95 believe an information source is more trustworthy than are 5-year-olds (Köymen \&

96 Tomasello, 2018).

\section{Method}

\section{Participants}

Sixty-one 5-year-olds $(M=5 ; 9$, Range $=5 ; 3-6 ; 2,32$ girls, 30 in the experimental condition) and 61 7-year-olds $(M=7 ; 6$, Range $=7 ; 3-7 ; 9,30$ girls, 31 in the experimental condition) participated in this study. All children were native German speakers with various socio-economic backgrounds, recruited and tested at urban daycares and schools. Additional 32 5-year-olds could not be included in the analysis, because they gave incorrect responses to false belief questions ( 24 children), failed to recall one or both reasons after cues ( 5 children), or refused to choose a partner ( 3 children). Additional 
106 eight 7-year-olds could not be included in the analysis due to incorrect responses to false

107 belief questions ( 5 children), failure to recall one or both reasons after cues ( 2 children), or

108 experimenter error ( 1 child).

\section{Materials}

110 For the cooperative game, we used an $85 \mathrm{~cm} \times 31 \mathrm{~cm}$ laminated background with

111 six panels with different colors, each depicting two sets of footprints leading up to two

112 different animals (see Figure 1). At the beginning, each animal was covered by a

113 cardboard box with a slot, and only its footprints were visible. The child and experimenter

114 had identical chips, depicting a desired item for an animal. They had to infer which animal

115 needs this item, which set of footprints belonged to this animal, and coordinate their

116 decisions by cashing their chips into the same correct box. If correct, the child would win

117 marbles to stack in an upright transparent tube with a finish line. For the partner choice,

118 the story describing the candidates was told using a 15-page booklet (see Appendix for the

119 pictures and the exact narration in English).

\section{Procedure}

121 The procedure was approved by the Research Ethics Committee of (anonymized). 


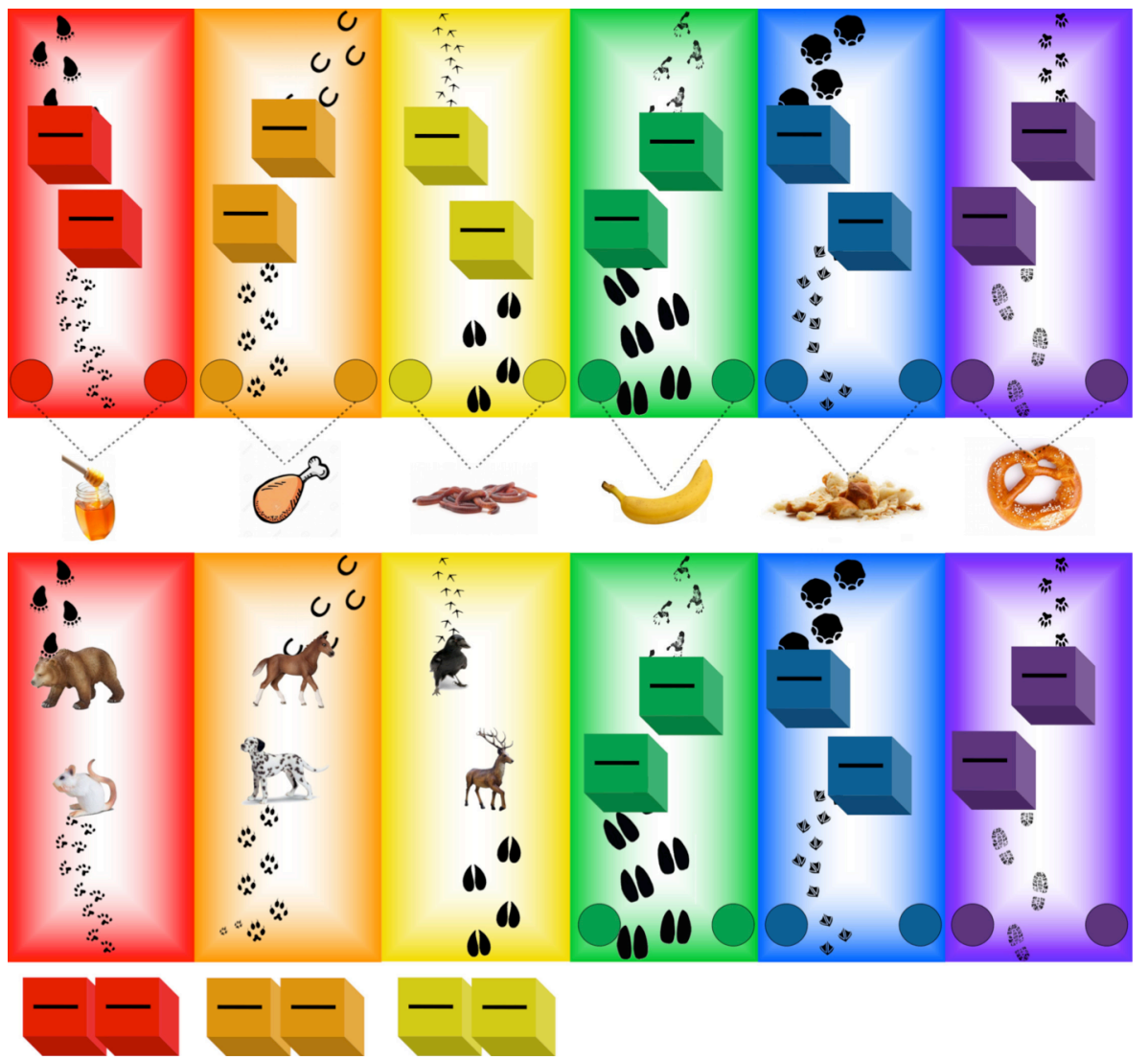

Figure 1. The cooperative warm-up game in its initial state (above) and before the picture narration (below); six panels, each with two boxes with a slot, and two tokens. Both tokens depict the same food item (right) and need both to be put into the box of the correct animal for a round to be successful. Panels 1-3 were used in warm-up, the remaining panels were used after the children chose a new partner.

For the cooperative game, the experimenter (E) explained to the child (C) the two were playing a detective game. $\mathrm{E}$ and $\mathrm{C}$ would have to infer together what animals were hidden under the two boxes based on their reading of the footprints, and place the two

126 identical "gifts" (food items printed on each chip, see Figure 1) in the box of the correct animal. If both $\mathrm{E}$ and $\mathrm{C}$ placed their chips in the same correct box, $\mathrm{C}$ would get two marbles. For instance, in the first round, E and C's chips each depicted a glass of honey. E asked $\mathrm{C}$ what animal might be happy about honey (proposed bear, if necessary). Then $\mathrm{E}$ and $\mathrm{C}$ decided which set of footprints belonged to the bear. Given that one set of

131 footprints belonged to a bear, the other to a mouse, $\mathrm{E}$ asked where $\mathrm{C}$ wanted to put her/his chip (reliably the box with bear traces) and asked $\mathrm{C}$ to put the chip there. E then inserted 
133 his own chip into the same box. They verified together that the animal under that box was 134 a bear and won two marbles.

135 In the second and third round, the procedure was parallel to the first, except that E

136 acted incompetently. After $\mathrm{C}$ entered her/his chip into the correct box, $\mathrm{E}$ first asked where

137 he should put his, but upon C's response remained doubtful about the right choice and

138 inserted his chip into the incorrect box, against any protest. After the third round, E

139 pointed out that $\mathrm{C}$ seemed to be a much better detective and would need a better partner

140 than E. The child could play the rest of the game (the remaining three panels in Figure 1)

141 with the new partner. E introduced the storybook about the two candidates. Story phase and partner choice

In the storybook, there were four main characters: two cartoon informants who

144 provide a claim and support it with a reason, and two photographed candidates who

145 evaluate the two informants' reasoning. We depicted the informants with cartoon figures

146 and the candidates with photographs so they were easily distinguishable. The first page

147 (see Appendix for the detailed narration) depicted both candidates side by side. E

148 explained that one was a good detective, just like $\mathrm{C}$, and the other was not, and that $\mathrm{C}$ had

149 to pay attention to what these two said in the story in order to know which was the good

150 one.

151 The informants had been painting with a brush, then they put the brush into one of

152 the two boxes (left unclear in the narration). After the informants left the room, a thief

153 stole the brush. From this point forward, the thief with the brush sticking out of his bag

154 was permanently visible next to the storybook. Next day, the two candidates entered the 


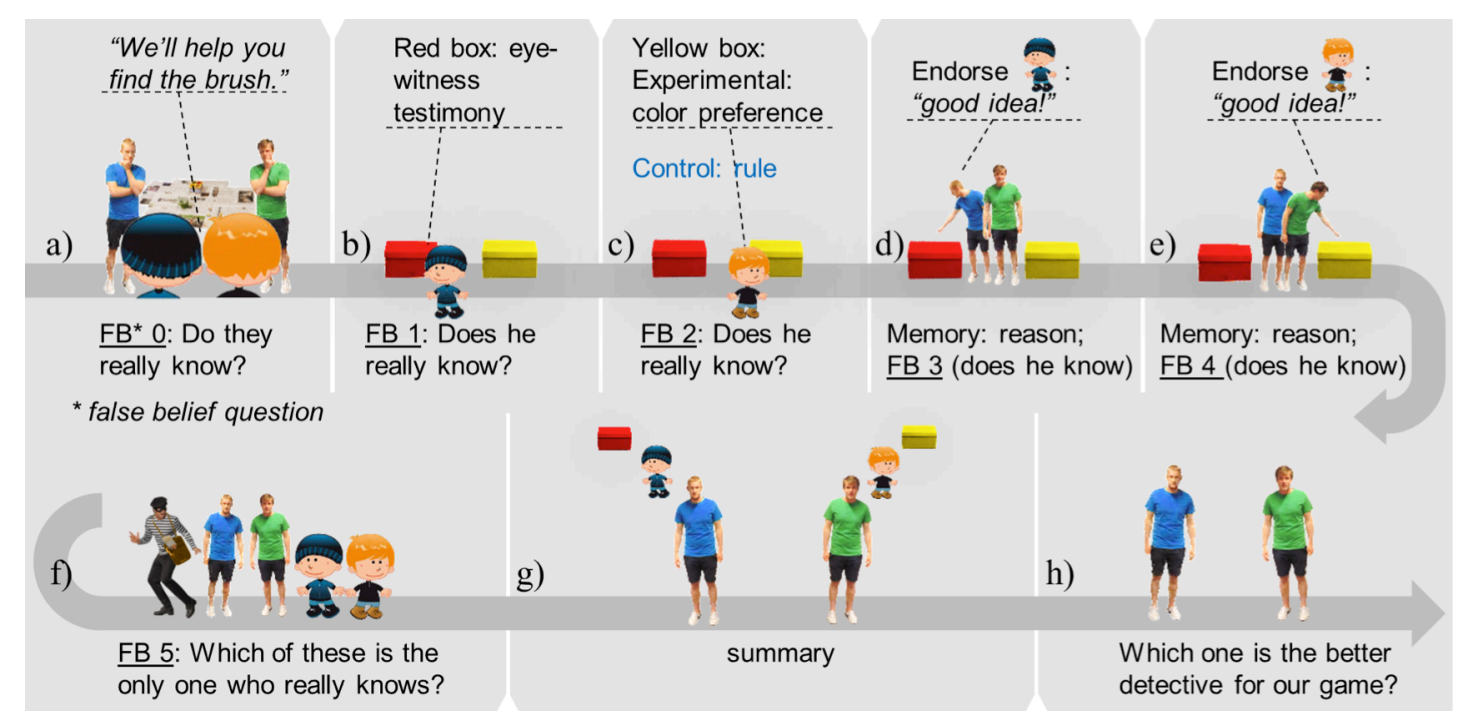

Figure 2. The key section of the narration. Characters and situation are introduced until including (a). Informants give a reason each for searching a box $(b, c)$. In the experimental condition, the good is paired with a poor reason, in the control with another good one. Candidates each endorse one of the informants (d, e). All facts are summarized (g) and the partner choice is given (h). From (a) through (f), children's false belief understanding is probed to exclude spontaneous ascriptions of knowledge.

155 room to do some painting but could not find the brush. The informants reappeared to help them out (see Fig. 2a).

At this point, the first false-belief question ("FB 0" in Fig. 2a) was introduced,

158 which concerned the two informants collectively ("Do these two know where the brush

159 really is?"), to make sure that children do not attribute knowledge to the informants.

160 Incorrect responses to this first question were corrected to establish the norm that answers

161 should be guided by information from the story, and not, e.g., guessing or inventing. Any

162 incorrect responses to any of the remaining five false belief questions led to exclusion

163 from the analyses.

165 box. One informant gave a good reason, namely eye-witness testimony: "because that is

166 where we put the brush yesterday, and that is also where I last saw it" (followed by false

167 belief question 1 "Does [the informant] really now where the brush is?", Fig. 2b). In the 
168 experimental condition, the other informant gave a poor reason based on color preference:

169 "because [color of this box] is my favorite color, and I like that color the most" (Fig. 2c).

170 In the control condition, this other informant gave another good reason based on rules:

171 "because that is where we always put the brush, and that's where it also belongs". In both

172 conditions, this statement was followed by false belief question 2 (Fig. 2c).

173 Next, one candidate endorsed the good reason based on eye-witness testimony. E

174 asked $\mathrm{C}$ to recall this reason (memory question), followed by false belief question 3 about

175 this candidate ("But does [this candidate] know where the brush really is?"; Fig. 2d). The

176 other candidate endorsed the other reason based on color preference/rules. E asked C the

177 same memory question about this reason, and false belief question 4 (Fig. 2e). Children

178 who responded incorrectly or not at all to either of the two memory questions (34 children,

$17927.9 \%$ ), received clues towards the correct answer. For the eye-witness testimony, the clue

180 was that it was about the previous day; for the rule-based reason, that it was something

181 that is always the case, and for the color preference-based reason, the question whether the

182 informant disliked the color. All but seven children gave the correct response after the

183 clues (these seven were excluded from the analyses). Then, given a page showing all five

184 characters including the thief (Fig. 2f), E asked the final, collective false belief question 5:

185 "If you look at these five guys, which of them is the only one who knows where the brush

186 really is?"

187 On a summary page (Fig. $2 \mathrm{~g}$ ) with the pairs of boxes, informants, and candidates

188 arranged such that they reflected who was related to whom and what in the story, E

189 repeated the informants' and candidates' statements to aid children's memory. E then

190 asked C (Fig. 2h): "Which of these two [point to the candidates] is the better detective for 
191 our game?" Upon C's pointing or naming, E asked why. After that, E explained that

192 neither of the candidates was able to make it to the school/daycare, so C finished the game

193 with E and won the reward. The sessions lasted about 15 minutes and were video-

194 recorded. Throughout the story, we counterbalanced the color of the boxes, look of the

195 informants, look of the candidates, and the presentation order of the two reasons.

196 For eight children, there were minor experimenter errors that did not lead to

197 exclusion, however. Five children did not receive the first non-critical false belief

198 question, which just reminded children not to guess. Two children were told (instead of

199 asked) about the first informant's false belief. One final child was told (instead of asked)

200 about both informants' and one candidate's false belief, but her explanation of her choice

201 was very detailed so we were ensured that she understood the story and the character's

202 false belief (“Because he rather responded to what happened last. You can't just go after

203 your favorite color ...”). These eight children answered all of the remaining questions

204 correctly.

205 Besides children's partner choices, we coded their justifications for their choice.

206 Our main interest was whether they mentioned the quality of the reason endorsed by that

207 partner. Responses thus fell into three categories:

$208-$ elaborate: children made reference to the reason, identifying the critical difference

209 between options with regard to the quality of the reasons and/or false belief of the

210 informants/candidates (e.g., "Because the favorite color has nothing to do with it",

211 "Because he said that's where they last saw it"); 
$212-$ simple: children only referred to the candidate/informant/box, without any

213 reference to the reasons (e.g., "Because he listened to him [the informant]",

214 "Because they looked in the red box");

$215-$ none: children gave irrelevant responses or no response (e.g., "Because blue is my

216 favorite color").

217 A second rater coded 32 of the 122 responses to the request for explanation, and the

218 agreement was $\kappa=.83$.

\section{Results}

220 As Figure 3 shows, in the experimental condition, $70 \%$ of the 5 -year-olds and $87 \%$

221 of the 7-year-olds chose the candidate who endorsed the good reason based on eye-witness

222 testimony; whereas in the control condition, this was the case with $35 \%$ of the 5 -year-olds

223 and $57 \%$ of the 7 -year-olds. In both age groups, the number of children who chose the

224 candidate endorsing the good reason based on eye-witness testimony was significantly

225 higher in the experimental condition than in the control condition $\left(\chi^{2}(1, N=61)=5.97, p\right.$

$226=.015$ for 5-year-olds, and $\chi^{2}(1, N=61)=5.59, p=.018$ for 7 -year-olds). 
228 good reason based on eye-witness testimony to chance in each condition using binomial

229 tests. In the experimental condition, children in both age groups chose this candidate

230 significantly above chance (5-year-olds: $p=.043,7$-year-olds: $p<.001$ ), whereas in the

231 control condition, their choice of this candidate was at chance level (5-year-olds: $p=.150$,

232 7-year-olds: $p=.585)$.

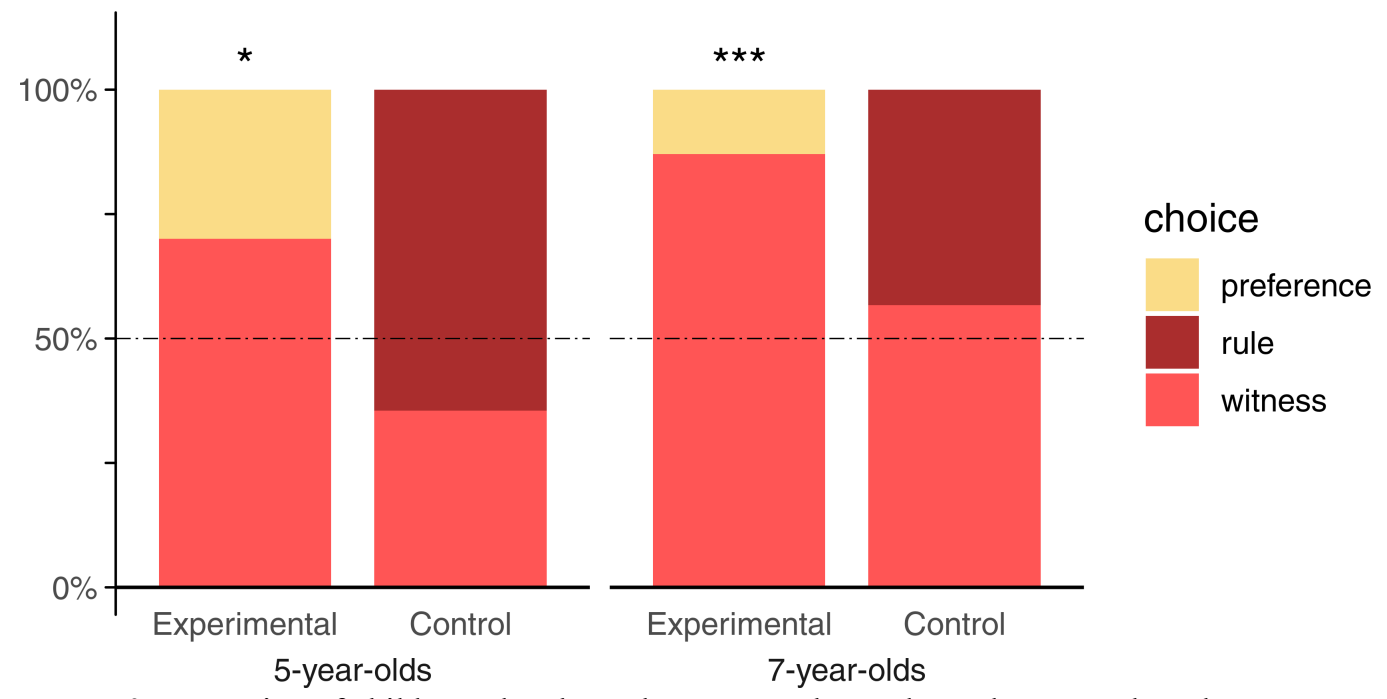

Figure 3. Proportion of children who chose the partners that endorse the reason based on eyewitness testimony. Asterisks indicate significance levels for participant groups that differ from chance in a binomial test $\left({ }^{*} p<.05 ;{ }^{* * *} p<.001\right)$. The dashed line indicates the chance level. 


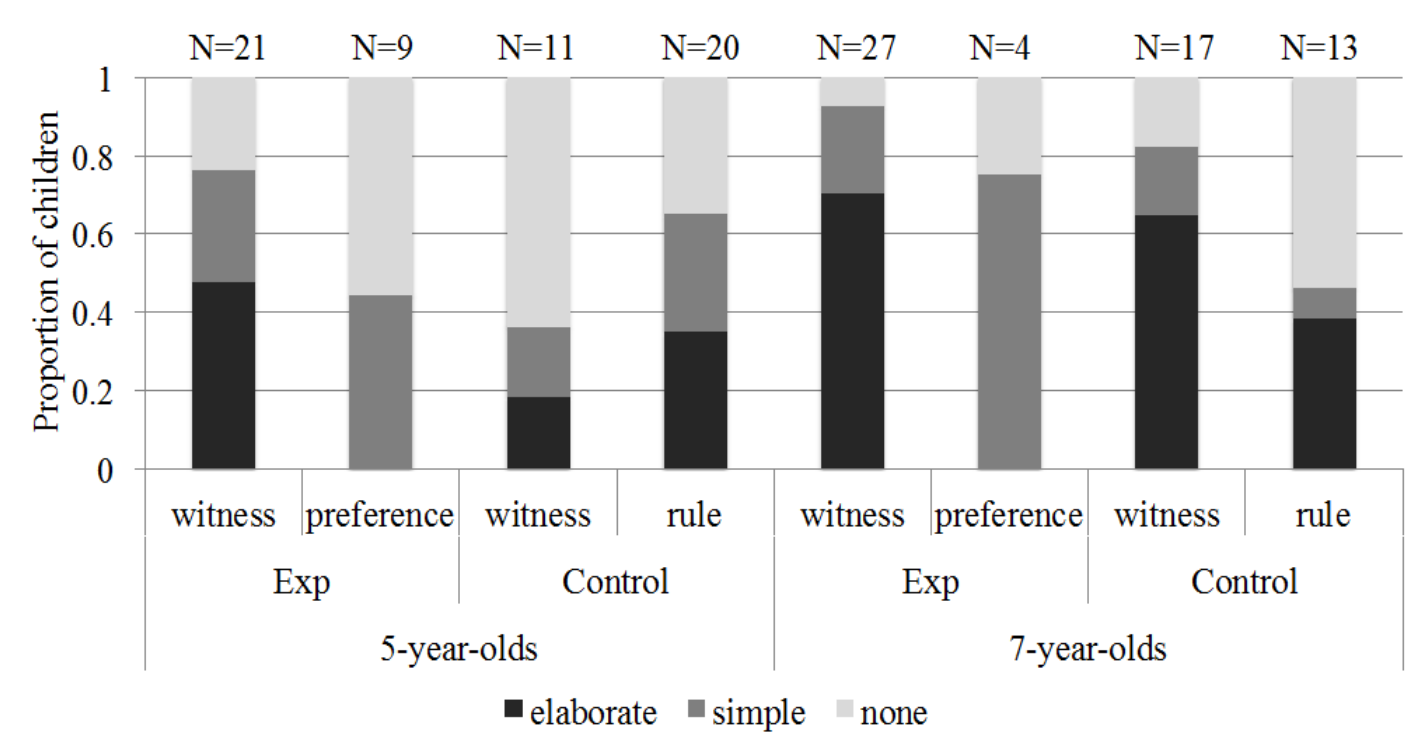

Figure 4. Children's explanations for their choice of candidates that endorsed the reasons based on eye-witness testimony, color preference, or rule.

Also, Figure 4 shows that in both conditions, 7-year-olds more often produced

234 elaborate explanations for their choice that referred to the relevant reason than did 5-year-

235 olds. This age difference was significant $\left(\chi^{2}(1, N=122)=7.48, p=.006\right)$.

\section{Discussion}

Our general findings were very clear. In the experimental condition, 7-year-olds chose the candidate who endorsed the good reason over the candidate who endorsed the

239 poor reason, and in the control condition, where both candidates endorsed good reasons, children chose both partners equally frequently. Five-year-olds, to the extent that they

241 could overcome the task demands (e.g., information tracking, false belief of the

242 characters), showed a similar pattern but much less reliably due to high dropout rates.

243 Crucially in both conditions, both candidates arrived at the wrong decision. Thus, our

244 study shows that children are able to evaluate the quality of reasons, and choose a partner

245 based on how well he/she responds to good (versus poor) reasons. 
Our study specifically rules out that children, if they selected the supporter of the

247 good reason, did so based on the assumption that this person is more knowledgeable or

248 simply right. Through the false belief questions, we made sure that children knew that

249 neither candidate knew better. Moreover, the control condition rules out the alternative

250 interpretation that children's choice of the candidate endorsing the good reason based on

251 eye-witness testimony in the experimental condition was due to an enduring belief that the

252 brush was still in the indicated box. If this were the case, children would have preferred

253 this candidate in the control condition as well.

254 One criticism for our findings would be that children in the experimental condition

255 did not evaluate the quality of the reasons or distinguished between good and poor

256 reasons, but simply distinguished between relevant and irrelevant information. However,

257 the bad reason ("yellow is my favorite color") is relevant to the proposal ("check the

258 yellow box") and to the task (choosing a box). If the informants had no information about

259 where the brush was and were taking a guess, saying "choose the yellow box, because

260 yellow is my favorite color" would not be irrelevant and in fact be a fine reason. Thus, in

261 our experimental condition children are evaluating whether the reason based on eye-

262 witness testimony is "better" or more "valid" than the reason based on color preference.

263 Another criticism would be the similarity in the wording of the two good reasons in the

264 control condition ("that is where I saw it yesterday" vs. "that is where we always put it")

265 and that children did not notice the difference between the two good reasons. We ensured

266 that children distinguished the two good reasons through memory questions ("do you

267 remember what the reason for the red/yellow box was?"), and only those children who

268 answered these questions correctly were included in the analysis. 
When explaining their choice, 7-year-olds more often than 5-year-olds produced explanations that referred to the relevant reason. This is in line with the finding that at

271 school age children start to produce more complex reasons for their decisions (Domberg et

272 al., 2018; Köymen \& Tomasello, 2018). It should be noted that explanations categorized

273 as "simple" (e.g., "Because he agreed with X") were ambiguous in terms of what guided

274 children's decision, but these explanations were, in a way, optimally informative.

275 Research on children's use of common ground supports this view (Köymen, Mammen, \&

276 Tomasello, 2016; Mammen, Köymen, \& Tomasello, 2018). That is, since the

277 experimenter knew the story, children might have assumed some common ground with

278 him and thought that it was obvious to the experimenter that the candidate who agreed

279 with one informant was better than the other candidate.

280 There was one limitation of our study however. Despite showing the same pattern

281 as 7-year-olds, 5-year-olds did have difficulty with the task. Our story was indeed a long

282 story with five characters and required children to keep track of these characters'

283 knowledge states, etc. Twenty-four 5-year-olds, who could not be included in the

284 analyses, answered at least one false belief question incorrectly and thus attributed

285 knowledge to one of the four characters. This high rate of incorrect responses to false

286 belief questions by 5-year-olds is surprising given the literature on false belief

287 understanding (Wellman et al., 2001). One potential explanation for this could be that

288 when children answered five false-belief questions in which the correct answer was

289 always "no", they might have found it pragmatically odd to answer "no" to all questions

290 and switched some of their answers to "yes". Moreover, children faced a non-standard 
291 false belief task with high memory load that was not designed to measure false belief

292 abilities but to safeguard our interpretation of the findings.

293 Future research could use simpler stories (perhaps with live actors) to investigate

294 how reliably 5-year-olds can evaluate other people's reasoning. Also, it would be worth

295 investigating whether social factors such as politeness, expertise, social status, group

296 membership would contribute to children's evaluation how others respond to good and

297 bad reasons, particularly in naturalistic settings. Children, even adults, might be prone to

298 social pressures and might occasionally favor bad reasoners over good reasoners in some 299 contexts.

300 To conclude, by age 7, children can reliably evaluate other people's reasoning and

301 reliably distinguish between speakers who submit to "reason" and those who do not. They

302 distinguish good reasons from poor ones, even if neither reason leads to a correct solution, 303 and prefer those partners who do the same. 
Birch, S. A. J., Vauthier, S. A., \& Bloom, P. (2008). Three- and four-year-olds spontaneously use others' past performance to guide their learning. Cognition, 107(3), 1018-1034. https://doi.org/10.1016/j.cognition.2007.12.008

308

309

310

311

312

Castelain, T., Bernard, S., \& Mercier, H. (2018). Evidence that two-year-old children are sensitive to information presented in arguments. Infancy, 23(1), 124-135. https://doi.org/10.1111/infa.12202

Castelain, T., Bernard, S., Van der Henst, J.-B., \& Mercier, H. (2016). The influence of power and reason on young Maya children's endorsement of testimony. Developmental Science, 19(6), 957-966. https://doi.org/10.1111/desc.12336

Corriveau, K. H., \& Harris, P. L. (2009). Choosing your informant: weighing familiarity and recent accuracy. Developmental Science, 12(3), 426-437. https://doi.org/10.1111/j.1467-7687.2008.00792.x

Corriveau, K. H., \& Kurkul, K. E. (2014). “Why does rain fall?”: Children prefer to learn from an informant who uses noncircular explanations. Child Development, 85(5), 1827-1835. https://doi.org/10.1111/cdev.12240

Domberg, A., Köymen, B., \& Tomasello, M. (2018). Children's reasoning with peers in cooperative and competitive contexts. British Journal of Developmental Psychology, 36(1), 64-77. https://doi.org/10.1111/bjdp.12213

Jaswal, V. K., \& Neely, L. A. (2006). Adults don't always know best: Preschoolers use past reliability over age when learning new words. Psychological Science, 17(9), 757-758. https://doi.org/10.1111/j.1467-9280.2006.01778.x 
326 Koenig, M. A. (2012). Beyond semantic accuracy: Preschoolers evaluate a speaker's

327

328

329

330

331

332

333

334

335

336

337 reasons. Child Development, 83(3), 1051-1063. https://doi.org/10.1111/j.14678624.2012.01742.x

Koenig, M. A., \& Harris, P. L. (2005). Preschoolers mistrust ignorant and inaccurate speakers. Child Development, 76(6), 1261-1277. https://doi.org/10.1111/j.14678624.2005.00849.x

Köymen, B., Mammen, M., \& Tomasello, M. (2016). Preschoolers use common ground in their justificatory reasoning with peers. Developmental Psychology, 52(3), 423429. https://doi.org/10.1037/dev0000089

Köymen, B., \& Tomasello, M. (2018). Children's meta-talk in their collaborative decision making with peers. Journal of Experimental Child Psychology, 166, 549-566. https://doi.org/10.1016/j.jecp.2017.09.018

Mammen, M., Köymen, B., \& Tomasello, M. (2018). The reasons young children give to peers when explaining their judgments of moral and conventional rules. Developmental Psychology, 54(2), 254-262. https://doi.org/10.1037/dev0000424

Mercier, H., Bernard, S., \& Clément, F. (2014). Early sensitivity to arguments: How preschoolers weight circular arguments. Journal of Experimental Child Psychology, 125, 102-109. https://doi.org/10.1016/j.jecp.2013.11.011

Mercier, H., \& Sperber, D. (2011). Why do humans reason? Arguments for an argumentative theory. Behavioral and Brain Sciences, 34(2), 57-74. https://doi.org/10.1017/S0140525X10000968

Mercier, H., \& Sperber, D. (2017). The enigma of reason. Cambridge, Massachusetts: Harvard University Press. 
349 Mercier, H., Sudo, M., Castelain, T., Bernard, S., \& Matsui, T. (2018). Japanese preschoolers' evaluation of circular and non-circular arguments. European Journal of Developmental Psychology, 15(5), 493-505. https://doi.org/10.1080/17405629.2017.1308250

$354 \quad$ Harvard Univ Pr.

355 Wellman, H. M., Cross, D., \& Watson, J. (2001). Meta-analysis of theory-of-mind

357 Wimmer, H., \& Perner, J. (1983). Beliefs about beliefs: Representation and constraining 358 function of wrong beliefs in young children's understanding of deception.

359 Cognition, 13(1), 103-128. https://doi.org/10.1016/0010-0277(83)90004-5 
Page 1. Here is a little story. At the end you can pick a new partner. One of these two: Blue Boris [point at BB] or Green Gustav [point at GG]. You need to pay attention, because one of them is a real good detective, just like you, and the other one is not. So listen well to what these two say.

Page 2. There are two other children, Mützen-Max [point at MM] and Blonde Ben [point at BB] and they met yesterday to paint together.

Page 3. They grabbed the brush and painted everything they could get their hands on.

Page 4. Mützen-Max and Blonde Ben tidied up the brush into the box and then went out the door.

Page 5. But at night, the thief came. He stole the brush from the box and ran off.

Page 6. [E unfolds the extra leaflet that from now on remains visible to 6

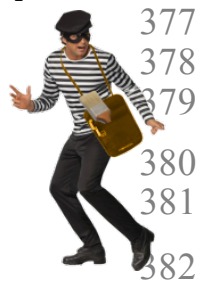
the side of the booklet.] The thief now has the brush in his bag. And the two boys, MützenMax and Blonde Ben, didn't notice it.

Page 7. And these two guys here, remember them?

\section{Free response}

Blue Boris and Green Gustav met this morning and they also wanted to paint. And what's missing?

\section{Response: the brush}

Right. And no one knows where it is. So the two pondered: Where can we find the brush?

Page 8. But they were lucky. Mützen-Max and Blonde Ben appeared again and said: Guys, we will help you find the brush.

False belief probe (1): Although, do they know where the brush really is?

\section{Negative response, otherwise correction.}

Page 9. Mützen-Max said:

Good reason (both conditions):

Check the red box,

because that is where we put the brush yesterday, and that's also where I last saw it.

False belief probe (2): But does Mützen-Max know where the
brush really is?

Negative response, otherwise drop.

Page 10. And Blonde Ben said:
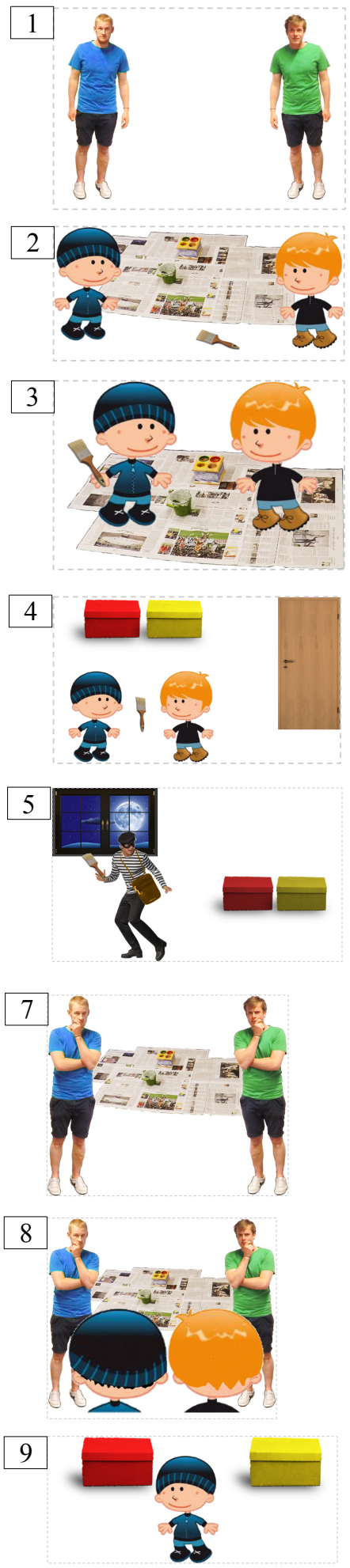
Poor reason (experimental condition):

Check the yellow box, because yellow is my favorite color, and I like that color the most.

Other good reason (control condition):

Check the yellow box, because that's where we always put the brush, and that's where it also belongs.

False belief probe (3): But does Blonde Ben know where the brush really is?

\section{Negative response, otherwise drop.}

Page 11. Next, Blue Boris said:

I think the idea with the red box is good!

Memory question: [name], do you remember what the reason for the red box was?

Correct response: reproduce reason; give cues if hesitant, correct if false.

False belief probe (4): But does Blue Boris know where the brush really is?

Negative response, otherwise drop.

Page 12. And Green Gustav said:

I think the idea with the yellow box is good!

Memory question: [name], do you remember what the reason for the yellow box was?

Correct response: reproduce reason; give cues if hesitant, correct if false.

False belief probe (5): But does Green Gustav know where the brush really is?

Negative response, otherwise drop.

Page 13. And now I have a question for you.

False belief probe (6): Which of these guys is the only one who knows where the brush really is?

\section{Correct response: the thief; drop if false.}

Page 14. So Mützen-Max thinks it's in the red box because he last saw it there, and Blue Boris thinks that's a good clue. And Blonde Ben thinks it's in the yellow box because [he likes yellow/it belongs there], and Green Gustav thinks that's a good clue.

Page 15. If you think hard about what these two said, which one is the better detective for our game?
10

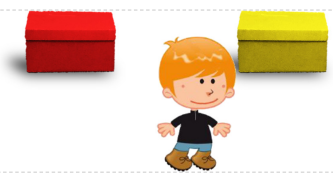

11

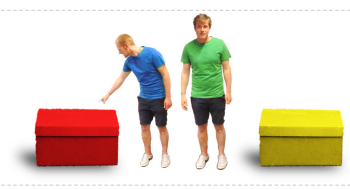

12

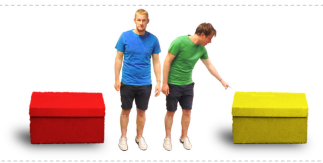

13

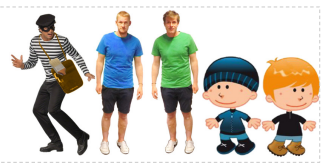

14

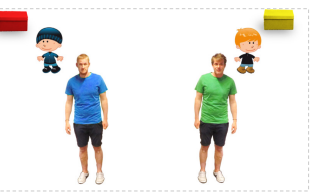

15

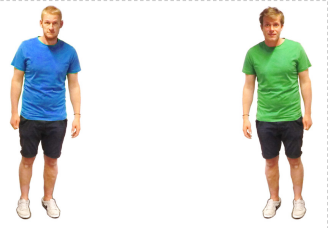

